\title{
THE COMPARATIVE EFFECTIVENESS OF CERTAIN CULICIFUGES UNDER LABORATORY CONDITIONS.
}

\author{
By A. BACOT, \\ Entomologist to the Lister Institute of Preventive Medicine, \\ and Private G. Talbot, R.A.M.C.
}

(With 1 Text-figure.)

CONTENTS.

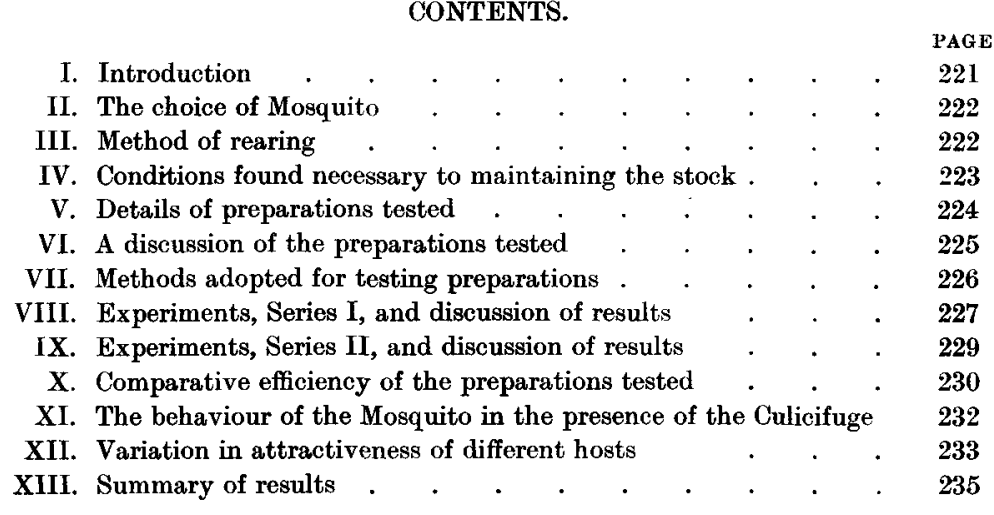

I. INTRODUCTION.

THE methods and experiments detailed in the following paper were devised for the purpose of determining for the War Office the comparative efficiency of certain Culicifuges, the work being carried out at the Lister Institute of Preventive Medicine.

Any preparation which will repel the attacks of mosquitoes, if only for a short period, is a desideratum in countries where these insects abound. In the case of soldiers in malarious countries, an effective culicifuge would be of great importance, as troops are necessarily exposed to risks not incurred by civilians, as, for instance, outpost and sentry duty at night, which debars the free use of mosquito curtains and at the same time restricts freedom of movement. In our opinion the experimental results obtained are sufficiently promising to justify their publication, together with the methods by which they were attained, in the hope that future work on these lines will establish a scientific basis for the use of culicifuges.

The bulk of the preparations were made up by Messrs Burgoynes from formulae collected by the War Office; these include Nos. 1-6, $9 a, 15 a$ and 16 . 
In addition, certain proprietary articles, Nos. 7, 10-14, 17, 19 and 22, recommended as efficient in keeping mosquitoes and midges at bay, were tested as well as a few preparations made up by the authors. As regards these latter the reasons for their inclusion are varied. Nos. 8, 9 and $9 b$, variants of 6 and $9 a$, were compounded with a view to checking the effect of altering the relative proportions of the active constituents and base. No. 15 was tried on account of its general high value as an insecticide; the formulae given being devised for another insecticidal purpose. Subsequently it was put up specifically as a culicifuge-No. $15 a$. Nos. 18 and 20 were given a trial on account of recommendations, while the inclusion of 21 was due to its time-honoured use by fishermen and field naturalists.

After making due allowance for the variable conditions and divergent numbers of mosquitoes present in the cages in the several tests, we suggest that our experimental evidence clearly discriminates between the several preparations tested; it shows that, while some afford a high degree of protection, others are of dubious value.

Without committing ourselves to the conclusion that the value of these preparations in the field against Anopheles mosquitoes will be exactly parallel to their use against Stegomyia fasciata (Aëdes calopus) under laboratory conditions, we trust that the work will afford a practicable comparative guide. On the other hand we fully appreciate the fact that from the point of view of pure science, we have dealt with only the fringe of a large subject, whilst as regards the practical issues, a really efficient culicifuge, one that will protect continuously for several hours, has yet to be found.

It is very desirable that further investigation should be made concerning the nature of the attraction possessed by man for the female mosquito, and the influence exercised by the culicifuge in combating it.

\section{THE CHOICE OF MOSQUITO.}

The choice of Aëdes calopus Meigen (= Stegomyia fasciata Fabr., Aëdes argenteus Poiret) for use in these experiments was due to the possession of a West African stock of this species by one of the authors, and by the fact that it can be easily reared in captivity. The females are renowned for their blood-sucking proclivities, feeding just as readily under laboratory conditions as when at liberty, the season of the year making no difference to either breeding or feeding, provided that the factors of the temperature and humidity are favourable.

\section{METHOD OF REARING THE MOSQUITOES.}

The eggs, laid on strips of filter paper, were immersed in tepid water to which was added a small quantity of brewers' yeast, and placed in an incubator at $95^{\circ} \mathrm{F}$. to hatch. After hatching they were transferred to another incubator kept at $80^{\circ} \mathrm{F}$. as the higher temperature was probahly responsible for the production of weakly adults. 
The food given to the larvae-brewers' yeast, pressed out of its wort-was chosen because it gave excellent results in speedy growth; further it was thought that there would be less danger of a poisoned bite occurring if a known organism were present in excess, than would be the case if a nutrient substance were added to the water, and the growth of organisms left to chance.

The only precaution needed with this food was to adjust the quantity of yeast to that of the water and number of larvae present. If too much is added, bacteria multiply to such an extent that a scum is produced on the surface, and is followed by the death of the larvae. The appearance of any scum on the water in the breeding jars should be a signal for a change of water, carried out as follows: The water is strained off through a piece of thin cotton or fine muslin, the jar refilled with fresh water of about the same temperature, and the muslin inverted in it.

For rapidity of rearing it was found more convenient to segregate the pupae and allow the adults to emerge in the incubator at $95^{\circ} \mathrm{F}$. than to place the jar containing the pupae in the experimental cage. In order to transfer the adults quickly, a waxed card cream jar, its bottom replaced by gauze, was inverted over the jars containing the pupae, security from falling or slipping off being obtained by a ring of stout paper tied round the neck of the jar, and projecting beyond its edge. The mosquitoes, as they emerged, ascended to the card receptacle. Each morning the stiff paper ring was removed and two pieces of card slipped across the top of the glass jar; the upper card was lifted and placed, with the receptacle containing the adult insects, on a piece of glass, the card withdrawn and the receptacle inverted for the purpose of counting the insects before transference to the experimental cage. This is effected by inserting receptacle and glass through a sleeve attached to a side of the cage (see description in section VII), removing the glass, and tapping smartly the sides of the receptacle to make the mosquitoes fly out.

An equal number of both sexes was transferred to the cages, but by dividing the pupae captured each day between the two jars allotted for the emergence of adults for each cage, the number of females transferred to each can be approximately adjusted.

Further details in regard to the breeding and bionomics of this species of mosquito can be obtained by reference to the report of the Yellow Fever Commission, vol. III (1916).

\section{CONDITIONS NECESSARY TO MAINTAINING A STOCK OF MOSQUITOES.}

Our first attempts at keeping a large stock of Stegomyia in the cages was not very successful owing to the heavy death-rate, due presumably to the dryness of the atmosphere, and to the numbers which fell into the water receptacles and were drowned. As it was evident that a much more humid atmosphere was required, the top of the cages and three of the sides, which were of gauze, were covered with waterproof paper. 
As food for the insects in intervals of blood-sucking, syrup (honey and water) was supplied, as shown in Fig. 1. A flask of water contained a tube formed of several thicknesses of blotting-paper with a piece laid horizontally over the top; on this a little syrup was poured and was kept constantly moist whilst water remained in the flask.

The presence of water to which the mosquitoes have access for drinking and oviposition, is essential to maintain them alive and feeding for any length of time; in order to prevent drowning, dried beech leaves were placed in the tins.

As a certain mortality is sure to occur, a continued supply of adult mosquitoes is necessary to replenish the cages. The eggs which are deposited on the leaves in the tins of water hatch, and the larvae thus obtained will afford a reserve of pupae from which the mosquitoes are bred.

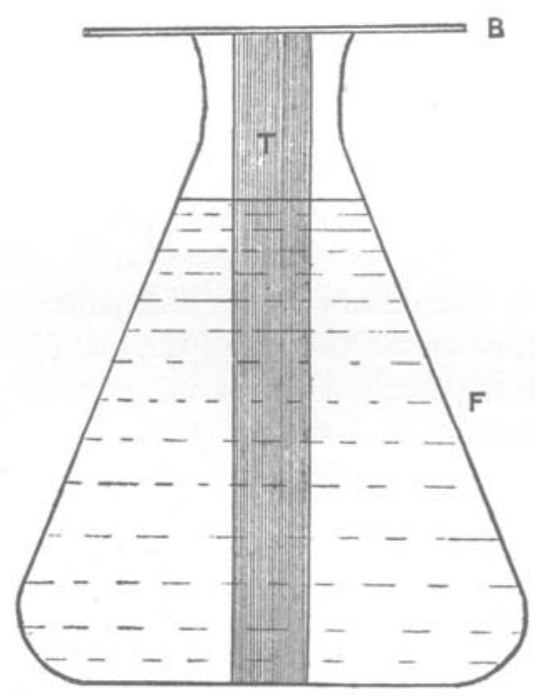

tig. 1. Arrangement for preventing evaporation of syrup. $F$. Flask containing water. T. Tube formed of blotting paper. $B$. Blotting paper to receive syrup, placed over top of flask.

\section{DETAILS OF PREPARATIONS TESTED.}

No. 1. Oil of Cassia, 1 oz., Brown Oil of Camphor, 2 ozs., Vaseline, Lanoline, or Salad Oil, 3 ozs. (Prepared with wax.)

No. 2. Oil of Peppermint, 1 oz., Oil of Cassia, 2 ozs., Vaseline, Spirit or Pond's Extract, 2 ozs.

No. 2 a. No 2 put up with wax.

No. 3. Bamber Oil (Citronella Oil, $1 \frac{1}{2}$ pts, Kerosene, 1 pt, Cocoanut Oil, 2 pts, Carbolic $1 \%$ ). (Prepared with wax.)

No. 4. Bergamot Oil, 1 pt, Kerosene, 16 pts. (Prepared with wax.).

. No. 5. Eucercit (Eucalyptus Oil, 2 ozs., liquid Carbolic Acid, 4 drops, Citronella Oil, 2 ozs.). (Prepared with wax.)

No. 6. Crude Coke Oven Naphthalene, 1 pt, Soft Soap, 3 pts.

No. 7. "Anti-mosquito Cream." (Prepared by Messrs Burgoynes.) 
No. 8. Refined Naphthalene and Camphor. Naphthalene 4, Camphor 1, Vaseline 2. No. 9. Crude Naphthalene (Coke Oven) 4, Camphor 1, Vaseline 2, Paraffin wax $\frac{1}{2}$.

No. 9 a. Crude Coke Oven Naphthalene, 3 pts, Camphor, 1 pt, Japan wax, 3 pts, Paraffin wax, 5 pts, Paraffin Molle, 5 pts.

No. $9 b$. Same as $9 a$ but with 10 pts Naphthalene.

No. 10. "Crude Parasitox." (Prepared by Messrs Heppel.)

No. 11. "Parasitox."

No. 12. "Mosquito Wax." (Prepared by Messrs Lawson and Co.)

No. 13. "Paraquit Wax." (Prepared by Messrs Lawson and Co.)

No. 14. "Paraquit Concentrated Soap." (Prepared by Messrs Lawson and Co.)

No. 15. Light Wood Oil Emulsion. (Light Wood Oil, 19 pts, Soft Soap, 10 pts, Caustic Soda, 5 pts, Water, 1 pt.)

No. 15 a. Light Wood Oil, $33 \%$ in a wax preparation.

No. 161. Carbolic Acid, 1 pt, Soft Soap, 3 pts.

No. 17. "Midge Cream."

No. 18. Quinine Sulphate (neutral), 1 gramme, Alcohol, $95 \%, 32$ c.c., Water, 11 c.c.

No. 19. Saffrol, Chlorobenzene and Chrysarobin, combined with Ethyl Chloride. (Put up by Messrs Hedley and Co.)

No. 20. Light Cedarwood Oil, 2 c.c., Paraffin Wax, 3 grs., Vaseline, about 0.75 gr.

No. 21. Oil of Turpentine, 2 c.c. Paraffin wax, 3 grs., Vaseline, 1 gr.

No. 22. "Lawson's Anti-mosquito Compound."

No. 22 a. "Lawson's Anti-mosquito Compound." (Second sample.)

\section{A DISCUSSION OF THE PREPARATIONS TESTED.}

Of the preparations tested in Table I, Nos. 1, 3, 4, 5, 6, 8, 9, 12, 13, 15 a, 22 and $22 a$ were prepared with wax; Nos. 2, 20 and 21 were of a greasy nature; Nos. 15, 18 and 19 were liquids, and Nos. 10,11 and 14 were prepared as soap.

It was found that the preparations made up with grease, or as soft soaps, had the advantage in ease and economy of application.

The composition of waxy preparations requires some nicety of adaptation in relation to the temperature in which it is proposed to use them; if this is not done they require warming in order to facilitate spreading, and to obtain an even coat, otherwise they tend to waste in use by flaking off, etc. As regards endurance, however, waxy preparations have a great advantage over greasy or soapy ones, as they form a more permanent covering to the skin, and more effectually retard volatilization. To secure any prolonged protection preparations ought certainly to be made up with wax.

Fluids form a class apart and require much more skill and care in application if waste is to be avoided; this applies more so to highly volatile fluids, as was the case with No. 19.

Soaps, if as hard as Nos. 10, 11 and 14, are best applied by first wetting the skin, otherwise they either coat the skin unequally, or flake off; if, however, they are of the right consistency they should be as easy to apply as grease or soft wax, though they suffer of course from the fact that perspiration will remove soap more readily than it will either wax or grease.

1 No. 16 was not tested against mosquitoes, as a preliminary trial on a small skin area showed that it caused considerable irritation. 
Many culicifuges lack efficiency owing to unsuitable preparation rather than to defects in their essential constituents. There is a general tendency on the part of makers to use too heavy a percentage of some inert base. Though in the case of a wax this may be useful in raising the melting point and in retarding volatilization, it must be condemned where the result is to diminish the effectiveness of the preparations. For instance, preparations 3, 4, 5 and 22 would doubtless give better results if compounded with less base and rendered easier to spread on the skin.

An ideal culicifuge should (1) spread easily so as to enable it to be quickly and evenly applied over the exposed area, while (2) at the same time it must be of such a consistency that it will adhere firmly to the skin, and (3) retard volatilization. In respect of points 1 and 3 , preparations need modification according to their intended use in tropical or temperate climates. (See also notes following Table I.)

The individual likes of people in regard to odours are varied and their dislikes so intense in some cases as to amount almost to physical discomfort, with the result that irritation caused by the bites would be preferred to the use of an objectionable culicifuge; some people greatly preferring the heavy odours of spices or gums to the cleaner if more penetrating smells of such substances as naphthalene and tarry or wood distillates.

These considerations make it hard to advise as to the best of a number of preparations giving approximately equal degrees of protection. Among troops and others compulsorily subjected to measures of malaria control, a preparation, the odour of which is greatly disliked, might fail because the majority would not apply it, or do so indifferently. The difficulty might be successfully met by adopting two classes of preparations.

The question of cost is also of importance; where large quantities are needed such preparations as $15 a, 9 b$, and 21 would easily outclass equally serviceable ones depending upon costly essential oils for their efficiency.

\section{METHODS ADOPTED FOR TESTING PREPARATIONS.}

The two cages used for carrying out the tests were similar to those employed for experimenting with this mosquito in West Africa under the auspices of the Yellow Fever Commission. The framework is of wood screwed together, the top and sides being of wire gauze with a circular hole 5 inches in diameter cut in one side to which is fastened a sleeve of mosquito netting. These cages measure on the inside 1 foot 6 inches in height, 2 feet in length, 1 foot $3 \frac{1}{2}$ inches in breadth. They are fully described and illustrated in the Reports of the Yellow Fever Commission, vol. III, pp. 169-172, 1916.

Each cage was used only once in 3 or 4 days, as the mosquitoes' desire for blood normally recurs at about 3-4 days intervals. On the occasions of the tests the mosquitoes were therefore ravenous.

The method adopted in testing a preparation was as follows: 
1. The arm, from wrist to elbow, was coated as evenly as possible with the preparation. One gramme was found to be sufficient for the purpose in most cases, and was used as the standard quantity; in a few instances the consistency of the preparation allowed of an economy, so that a few tests were carried out, using $\cdot 75 \mathrm{grm}$. In the case of the liquid preparations, Nos. 18 and 19, larger quantities were necessary, in order to completely coat the desired area of skin.

The hand, during the exposure of the arm in the cage, both in tests and controls, was covered by a rubber glove, it being necessary to restrict the bites to the forearm, owing to the fact that on many parts of the hand the skin reaction is so slight that it is not possible to enumerate bites with accuracy.

In the first series of experiments the arm, after treatment, was covered by the sleeve for 15 minutes to allow of some volatilization, before exposure in the cage for 10 minutes.

In the earlier trials with preparations 1-9 the control exposure of the untreated arm for a similar period, followed immediately after the test. It was found, however, with some preparations, that very few, if any, attacks were made by the insects under these circumstances. This presumably was due to the persistence of the vapour in the cage preventing the mosquitoes from detecting the presence of food. In all subsequent tests, therefore, a longer or shorter interval, usually of from 2-4 hours, was allowed between the test and the control.

2. In the second series of experiments the procedure was the same, except that the arm, after treatment, was exposed to the air for periods of from 2-5 hours before insertion in the cage.

It is to be noted that tests made in the laboratory under the conditions described are really more severe than would be the case were the preparations used in the ordinary way out of doors. Under ordinary circumstances the insects would have a greater range of choice, for even if all the population of a district were similarly protected, there would still be the chance of feeding on other animals; in the laboratory the choice was restricted to a preference for the treated or untreated arm of A. B. or G. T.

\section{EXPERIMENTS, SERIES I.}

Prior to conducting the first series of trials a preliminary census was made in order to ascertain the number of feeding females in the respective cages. On May 21st, 1918, an unprotected arm was exposed in each cage; the number of bites recorded was: Cage A, 41 bites; cage B, 43 bites.

The preparations were tested according to the method already explained. The results are given in Table I. 
Table I.

Preliminary Tests of Culicifuges.

(15 minutes after application.)

\begin{tabular}{|c|c|c|c|c|c|c|c|c|}
\hline 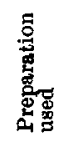 & 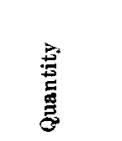 & 胥 & 造 & 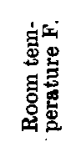 & 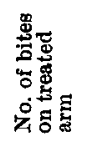 & 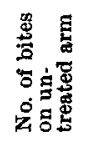 & 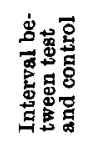 & 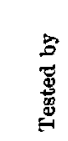 \\
\hline \multirow{2}{*}{1} & $\int 1 \mathrm{gr}$. & B. & 24. v. 18 & $71^{\circ}$ & 0 & 30 & 0 & \\
\hline & $\{\cdot 75 \mathrm{gr}$. & B. & 25. vi. 18 & $66^{\circ}$ & 0 & 27 & $4 \mathrm{hrs}$. & \\
\hline \multirow{2}{*}{2} & $\int 1 \mathrm{gr}$. & A. & 25. v. 18 & $71^{\circ}$ & 0 & 0 & 0 & \\
\hline & 1, & A. & 4. vii. 18 & $71^{\circ}$ & 0 & 35 & $5 \frac{1}{2} \mathrm{hrs}$. & \\
\hline \multirow{2}{*}{3} & $\{1$ & B. & 27. v. 18 & $68^{\circ}$ & 12 & 6 & 0 & \\
\hline & $\{1 \%$ & B. & 1. vii. 18 & $73^{\circ}$ & 4 & 33 & $3 \mathrm{hrs}$. & \\
\hline \multirow{2}{*}{4} & $\int 1 \%$ & A. & 29. v. 18 & $69^{\circ}$ & 15 & 5 & 0 & \\
\hline & 11, & A. & 1. vii. 18 & $73^{\circ}$ & 18 & 50 & $3 \mathrm{hrs}$. & \\
\hline \multirow{2}{*}{$\mathbf{5}$} & (1), & B. & 31. v. 18 & $70^{\circ}$ & 5 & 16 & 0 & \\
\hline & $\{1$, & B. & 4. vii. 18 & $71^{\circ}$ & 5 & 48 & $5 \frac{1}{2} \mathrm{hrs}$. & \\
\hline 6 & $1 \%$ & A. & 1. vi. 18 & $71^{\circ}$ & 5 & 0 & 0 & \\
\hline \multirow{2}{*}{7} & 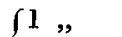 & B. & 4. vi. 18 & $69^{\circ}$ & 3 & 20 & 0 & \\
\hline & ( $75 \mathrm{gr}$. & A. & 8. vii. 18 & $73^{\circ}$ & 23 & 69 & $5 \mathrm{hrs.}$ & \\
\hline 8 & $1 \mathrm{gr}$. & A. & 5. vi. 18 & $69^{\circ}$ & 2 & 1 & 0 & \\
\hline \multirow{2}{*}{9} & $\int^{1}$, & B. & 7. vi. 18 & $69^{\circ}$ & 0 & 13 & 0 & \\
\hline & $\{\cdot 75 \mathrm{gr}$. & B. & 28. vi. 18 & $70^{\circ}$ & 1 & 31 & $3 \mathrm{hrs}$. & \\
\hline 10 & $1 \mathrm{gr}$. & A. & 10. vi. 18 & $\left\{\begin{array}{l}67^{\circ} \\
68^{\circ}\end{array}\right.$ & 0 & $7\}$ & 3 & \\
\hline 11 & 1 ", & B. & 11. vi. 18 & $\left\{\begin{array}{l}68^{\circ} \\
69^{\circ}\end{array}\right.$ & 0 & $\left.{ }_{20}\right\}$ & 4, & \\
\hline 12 & 1 , & A. & 14. vi. 18 & $69^{\circ}$ & 10 & 23 & 2 , & \\
\hline 13 & 1, & B. & 14. vi. 18 & $69^{\circ}$ & 16 & 30 & 1, & G.T. \\
\hline 14 & & B. & 17. vi. 18 & $66^{\circ}$ & 10 & 13 & $2 \frac{1}{2}$, & G.T. \\
\hline 15 & 1 & A. & 17. vi. 18 & $\left\{\begin{array}{l}66^{\circ} \\
64^{\circ}\end{array}\right.$ & 0 & $11\}$ & 19, & G.T. \\
\hline $15 a$ & 1 ", & A. & 30. vii. 18 & $75^{\circ}$ & 0 & 119 & $1 "$ & A.B. \\
\hline 17 & $.75 \mathrm{gr}$. & A. & 25. vi. 18 & $66^{\circ}$ & 30 & 45 & 2, & \\
\hline 18 & 2 c.c. & A. & 28. vi. 18 & $68^{\circ}$ & 33 & 20 & 4, & \\
\hline 19 & 3.5 grs. & B. & 26. vii. 18 & $70^{\circ}$ & 52 & 30 & 5, & A.B. \\
\hline 20 & $1 \mathrm{gr}$. & A. & 6. viii. 18 & $\left\{\begin{array}{l}69^{\circ} \\
70^{\circ}\end{array}\right.$ & 22 & $19\}$ & $2-4 \mathrm{hrs}$. & G.T. \\
\hline 21 & $1 \quad$, & A. & 9. viii. 18 & $\left\{\begin{array}{l}69^{\circ} \\
70^{\circ}\end{array}\right.$ & 0 & $100\}$ & $2 \frac{1}{2} \mathrm{hrs}$. & G.T. \\
\hline 22 & $1 \quad$ & A. & 12. viii. 18 & $74^{\circ}$ & 22 & 91 & 2 & G.T. \\
\hline $22 a$ & $1 \quad "$ & A. & 13. ix. 18 & $\left\{\begin{array}{l}64^{\circ} \\
66^{\circ}\end{array}\right.$ & 0 & $21\}$ & & G.T. \\
\hline
\end{tabular}

(1) Nos. 6 and 8 were not easy to apply, and the essential ingredients were better combined in No. 9 .

(2) No. 19, owing to its volatile nature, precluded any possibility of using a measured quantity. The fluid was sprayed over the forearm until the skin was completely covered; about 3.5 grs. were needed, but there was some unavoidable waste. 
(3) No. 22 was impossible to apply satisfactorily, even by the use of heat or water; most of it flaked off, but left a strong odour behind. Put up in altered form as $22 a$ it still left much to be desired as regards its spreading properties, after the lapse of an hour or more becoming too dry to adhere properly to the skin.

The preliminary trials indicated that some of the preparations showed the maximum degree of efficiency in relation to the conditions of the test, whereas others only afforded a partial degree of protection.

Between the first census of bites and a second one carried out on June 20th, when 39 bit in cage $A$, and 59 in cage $B$, there was apparently a considerable reduction in the biting population of the cages. It is not easy to estimate the amount of this reduction, or exactly when it occurred, owing to the early method of allowing no interval between the insertion of the treated and the control arm-which confused the issue. The reduction must however be attributed to the heavy death rate occasioned by drowning and drought. Subsequently, after the cages had been covered in by waterproof paper, and leaves had been placed in the water receptacles, the death rate was minimised and the population increased, any fluctuations being due either to the introduction of recently reared adults or to deaths owing to the natural completion of the life cycle.

The early tests were repeated after the population had increased, so that the trials of the preparations were brought into conformity with the others. In Table I both tests will be found bracketed against the preparation.

In a few tests (Preparations Nos. 10, 11, 15, 20, 21 and 22) the temperature altered during the period between test and control; in such cases both temperatures are recorded.

\section{EXPERIMENTS, SERIES II.}

\section{The Duration of the Period of Effectiveness.}

For the purpose of military use it is of special importance that the protection afforded should cover as long a period as possible. A further series of trials was therefore arranged in order to determine for what period protection would be afforded.

Preliminary trials in-connection with this series showed that it was useless to expect protection to be conferred for a longer period than a few hours at most, the better preparations affording practically no protection after the lapse of 16 and 8 hours respectively. The period of trial was therefore reduced first to 5 , then to 3 , and finally to 2 hours.

The efficient culicifuges, comprising Nos. $1,2 a, 5,9 a, 9 b, 10,11,15 a$, 21 and $22 a$ were alone included in this series of trials. The results obtained are given in Table II. 
Table II.

The Duration of the Period of Efficiency of certain Culicifuges.

\begin{tabular}{|c|c|c|c|c|c|c|c|c|c|c|c|c|}
\hline \multirow[b]{2}{*}{$\begin{array}{l}\text { Prepara- } \\
\text { tion used }\end{array}$} & \multirow{2}{*}{\multicolumn{2}{|c|}{$\begin{array}{l}\text { Quantity } \\
\text { used }\end{array}$}} & \multirow[b]{2}{*}{ Cage } & \multirow[b]{2}{*}{ Date } & \multirow[b]{2}{*}{$\begin{array}{l}\text { Room } \\
\text { tempera } \\
\text { ture F. }\end{array}$} & \multicolumn{2}{|c|}{2 hrs after application } & \multicolumn{2}{|c|}{$3 \mathrm{hrs}$ after application } & \multicolumn{2}{|c|}{5 hrs after application } & \multirow[b]{2}{*}{$\begin{array}{r}\text { Test } \\
\text { by }\end{array}$} \\
\hline & & & & & & $\begin{array}{c}\text { No. of bites } \\
\text { on treated } \\
\text { arm }\end{array}$ & $\begin{array}{l}\text { No. of bites } \\
\text { on untreated } \\
\text { arm }\end{array}$ & $\begin{array}{l}\text { No of bites } \\
\text { on treated } \\
\text { arm }\end{array}$ & $\begin{array}{l}\text { No. of bites } \\
\text { on untreated } \\
\text { arm }\end{array}$ & $\begin{array}{c}\text { No. of bites } \\
\text { on treated } \\
\text { arm }\end{array}$ & $\begin{array}{c}\text { No. of bites } \\
\text { on untreated } \\
\text { arm }\end{array}$ & \\
\hline 1 & $.75 \mathrm{~g}$ & & B. & 19. vii. 18 & $71^{\circ}$ & 12 & 30 & - & 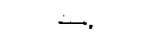 & 一 & 一 & A.1 \\
\hline 1 & $\cdot 75$ & , & A. & 15. vii. 18 & $70^{\circ}$ & - & -- & - & - & 41 & 17 & G.I] \\
\hline $2 a$ & 1 & , & B. & 2. จiii. 18 & $69^{\circ}$ & 8 & 76 & - & - & - & 一 & A.1 \\
\hline $2 a$ & 1 & , & B. & 6. viii. 18 & $\left\{\begin{array}{l}69^{\circ} \\
70^{\circ}\end{array}\right.$ & 27 & $42\}$ & - & - & $\longrightarrow$ & - & G.I \\
\hline 5 & .75 & , & A. & 23. vii. 18 & $72^{\circ}$ & 36 & 37 & - & 一 & - & 一 & G.I \\
\hline $9 a$ & 1 & , & B. & 13. viiii. 18 & $75^{\circ}$ & 29 & $48^{*}$ & - & - & - & 一 & G.] \\
\hline $9 a$ & .75 & , & B. & 12. vii. 18 & $70^{\circ}$ & 一 & - & 一 & - & 50 & $\left\{\begin{array}{c}\text { not } \\
\text { controlled } \mid\end{array}\right.$ & A.F \\
\hline $9 b$ & 1 & , & B. & 23. vii. 18 & $72^{\circ}$ & - & - & 35 & 46 & - & - & A.r \\
\hline 10 & .75 & , & B. & 16. vii. 18 & $71^{\circ}$ & 49 & 68 & - & - & - & 一 & A.I \\
\hline 11 & 75 & ", & A. & 19. vii. 18 & $71^{\circ}$ & 81 & $\left\{\begin{array}{c}\text { not } \\
\text { controlled }\end{array}\right.$ & $\longrightarrow$ & 一 & - & - & G.I \\
\hline $15 a$ & 1 & , & A. & 2. viii. 18 & $69^{\circ}$ & 37 & 74 & - & 一 & $\longrightarrow$ & - & G.I \\
\hline $15 a$ & 1 & , & B. & 30. vii. 18 & $75^{\circ}$ & 一 & 一 & 21 & $64 \dagger$ & - & - & A.F \\
\hline 21 & 1 & ", & B. & 10. viii. 18 & $75^{\circ}$ & 27 & 68 & - & - & - & - & A.E \\
\hline $22 a$ & 1 & , & A. & 16. ix. 18 & $67^{\circ}$ & 25 & 19 & - & - & - & - & G.T \\
\hline
\end{tabular}

Of the preparations used in the tests shown in Table II, with the exception of the proprietary ones, Nos. 10 and 11 (which were unaltered), those not already made up with wax were recompounded in conformity with the others. This change was necessary in order to prevent their being at a disadvantage in the long period trials in comparison with Nos. 1, 5, 10 and 11.

\section{COMPARATIVE EFFICIENCY OF THE PREPARATIONS TESTED.}

A percentage of the bites obtained in the trials set forth in Table II, out of the total number recorded gives an index to the comparative efficiency of these preparations. This index is shown in Table III.

Table III.

Index of Comparative Efficiency of Culicifuges.

Preparation
tested
1
1
1
$2 a$
$2 a$
5
$9 a$
$9 b$
10
$15 a$
$15 a$
21
$22 a$

\begin{tabular}{|c|c|c|c|c|}
\hline \multicolumn{3}{|c|}{ Time after application } & \multirow{2}{*}{$\begin{array}{c}\text { Percentage } \\
\text { of bites }\end{array}$} & \multirow{2}{*}{$\begin{array}{c}\text { Tested } \\
\text { by }\end{array}$} \\
\hline$2 \longdiv { \text { hours } }$ & 3 hours & 5 hours & & \\
\hline$x$ & $\therefore$ & - & 28 & A.B. \\
\hline - & - & $x$ & 70 & G.T. \\
\hline$x$ & - & 一 & 9 & A.B. \\
\hline$x$ & - & - & 39 & G.T. \\
\hline$x$ & - & 一 & 49 & G.T. \\
\hline$x$ & $\dot{-}$ & $\longrightarrow$ & 37 & G.T. \\
\hline-- & $x$ & - & 43 & A.B. \\
\hline$x$ & - & - & 43 & A.B. \\
\hline- & $x$ & $\ldots$ & 24 & A.B. \\
\hline$x$ & - & - & 33 & G.T. \\
\hline$x$ & - & - & 28 & A.B. \\
\hline$x$ & - & - & 56 & G.T. \\
\hline
\end{tabular}


No importance is to be attached to the difference in the absolute number of bites as between one preparation and another, owing to the fluctuation in the number of hungry female mosquitoes present. We would also point out that the individual idiosyncrasies of the two experimenters in respect of their attraction for Stegomyia fasciata, may have influenced the results. It will be noted in the two parallel tests with No. $2 a$, that the percentage of bites is very different; in the case of A. B. only $9 \%$ bit, while in the case of $G$. T. $39 \%$ bit. The only other test that permits of comparison in this respect is in the case of No. $15 a$; in the two hours test $33 \%$ bit G. T., while in a three hours test only $23 \%$ bit A. B.

If we analyse the first case, that of $2 a$, we notice that, whereas $\mathbf{A}$. B. tested it on August 2nd, G. T. tested four days later on August 6th, the same cage being used. On August 1st about 16 females were added to the cage and these would normally bite on the 3rd and certainly on the 6th. On August 2nd, about 12 females were added, which would also bite on the 6th. We have therefore an addition of about 28 females ready to bite on the 6th. It happened, however, that a total of only 69 bit on the second occasion, as against 84 on the first. Allowing for the greater attraction, subsequently shown to be possessed by G. T. for the mosquito (see Section XII), the difference in the total number of bites in the two results must be mainly due to some mortality between the two dates, or to some unexplained disinclination to suck blood on the part of a number of the females.

If we omit the question of the difference of attractiveness of $\mathrm{A}$. B. and G. T., the value of the preparations tested would rank, on the basis of Table III, as follows: $2 a, 1,15 a$, and 21 almost on a parity, followed by $9 a, 10$ and 5 in order, but if an allowance be made for individual attractiveness, the figures point to $15 a$ as the most efficient culicifuge.

The following classification of the preparations is in accordance with the percentage of bites in relation to the total number received in test and control. In drawing it up no allowance has been made for the greater preference of the insects for one of the experimenters over the other, as it was only in the later series of trials that this preference was noted and recorded. As shown in the discussion of the results of the long period trials this factor may be of considerable importance and in judging the results allowance must be made for it.

\section{Preliminary Trials.}

$0 \%$. Nos. $1,2,10,11,15,15 a, 21$ and $22 a$.

$3 \%$. No. 9 (in the first trial no bites were recorded).

$9 \%$. No. 5 (on result of second trial).

$10 \%$. No. 3 (on result of second trial).

$19 \%$. No. 22 .

$25 \%$. No. 7 (on result of second trial).

$26 \%$. No. 4 (on result of second trial).

$30 \%$. No. 12 .

$35 \%$. No. 13 . 
$40 \%$. No. 17.

$43 \%$. No. 14 .

$53 \%$. No. 20 .

$62 \%$. No. 18 .

$63 \%$. No. 19 .

\section{Long Period Trials.}

2 hours.

$28 \%$. Nos. 1 and 21 .

$29 \%$. No. $2 a$ (combined result of two trials: A. B. shows $9 \%$. G. T. shows $39 \%$ ).

$33 \%$. No. $15 a$.

$38 \%$. No. 9 a.

$42 \%$. No. 10 .

$49 \%$. No. 5 .

$56 \%$. No. 22 a.

3 hours.

$25 \%$. No. $15 a$.

$43 \%$. No. 9 b.

5 hours.

$71 \%$. No. 1 .

\section{BEHAVIOUR OF THE MOSQUITO IN THE PRESENCE OF THE CULICIFUGE.}

In the cage the untreated arm is generally attacked by the insects after the lapse of not longer than two minutes. A treated arm, where the preparation used is not effective, is attacked within the same period. After a lapse of five minutes all the hungry females will have generally attacked.

We noted, during the first series of tests (see Table I) that with effective preparations, the insects sometimes settled on the treated arm and walked over it, flying off again without feeding, being apparently indifferent to the odour.

Again, with most of the preparations the wounds occurred on the wrist and towards the elbow, such localised attacks being possibly due to the proximity of the untreated areas of hand and arm.

On one occasion, in applying a preparation, a narrow streak was inadvertently left untreated, and the insects not only bit on that area, but also through the preparation in the area immediately adjacent, no bites being found elsewhere.

Our observations therefore show that the preparations are only likely to be effective within a very restricted range. Moreover, the entire exposed area must be covered, and steps must be taken for renewed application, even with the best of the culicifuges experimented with, at intervals of not more than two hours.

On the basis of these observations we are inclined to put forward a tentative theory to the effect that the action of the culicifuges is rather to obscure the human odour than to repel the insects. 


\section{EXPERIMENTS CONCERNING THE DEGREE OF ATTRACTION EXHIBITED BY DIFFERENT INDIVIDUALS FOR MOSQUITOES.}

It is a matter of general comment that some individuals are more prone to mosquito attacks than others. Finlay (1912) records that natives of Africa are least liable to attack and that people of northern races recently arrived in the tropics are most persecuted; he considered it probable that this preference depended upon the thickness of the skin, and the condition of the capillary circulation of the skin. In regard to the Yellow Fever mosquito (the species used in these experiments) Goeldi (1912) considered that the presence of perspiration attracted both sexes. The French investigators, Marchoux, Salimbeni and Simond (1912), concluded from experiments that, although Stegomyia fasciata readily bites both negro and red skinned races, it shows a preference for white skinned people. They further showed that this mosquito exhibited preferences among whites for young and vigorous persons, over aged, and anaemic ones. It is also very generally asserted that in the tropics seasoned whites enjoy a certain amount of immunity at the expense of fresh arrivals.

As this factor of preference on the part of the mosquitoes for one of the experimenters was apparently influencing our results (see pp. 234-5), we planned a series of experiments in order to ascertain if possible some measure of its importance, and carried them out as opportunity permitted. The method adopted was similar to that already described in regard to the testing of culicifuges (see Section VII), but for the purpose of these trials two persons exposed their untreated arms simultaneously in the same cage for 10 minutes.

The following data relating to the persons who exposed their arms in the cages may be of interest.

A. B. Age 51. Has never resided out of England until three years ago when he spent 13 months in W. Africa. During and since that period has regularly allowed mosquitoes to feed upon his arms. Shows very slight reaction to bites.

G. T. Age 35. Save for two months' residence in N. France, has always lived in England. Has allowed mosquitoes to bite him frequently during the past four months, and showed a marked reaction to their bites, but seems to have gained some measure of immunity since the commencement of this research.

H. Age 38. Born in Australia and lived for many years in Queensland; has resided in England for the past six years. Shows very slight reaction to bites.

I. Age 48. Fourteen years ago resident off and on in Tropical South America for about ten years. Has since been resident in England. Shows marked reaction to bites.

J. Age 18. Has never resided out of England. Shows a marked reaction to bites.

K. Age 27. Has never resided out of England. Shows a marked reaction to bites.

L. Age 54. About a year ago resided for 13 months either in Greece or Malta. Has never lived in the tropics. Shows slight reaction to bites.

M. Age 31. Never resident out of England. Shows a marked reaction to bites. 
Table IV.

$\begin{array}{ccc}\begin{array}{c}\text { Number of } \\ \text { experiment }\end{array} & \begin{array}{c}\text { Initial of } \\ \text { experimenter }\end{array} & \begin{array}{c}\text { Number } \\ \text { of bites }\end{array} \\ 1 & \text { A.B. } & 10 \\ 2 & \text { A.B. } & 3 \\ 3 & \text { A.B. } & 37 \\ 4 & \text { A.B. } & 16 \\ 5 & \text { A.B. } & 23 \\ 6 & \text { A.B. } & 16 \\ 7 & \text { A.B. } & 6 \\ 8 & \text { G.T. } & 6 \\ 9 & \text { G.T. } & 8 \\ 10 & \text { G.T. } & 62 \\ 11 & \text { G.T. } & 27 \\ 12 & \text { G.T. } & 4\end{array}$

$\begin{array}{ccc}\begin{array}{c}\text { Percentage of } \\ \text { total bites }\end{array} & \begin{array}{c}\text { Initial of } \\ \text { experimenter }\end{array} & \begin{array}{c}\text { Number } \\ \text { of bites }\end{array} \\ 17 \% & \text { G.T. } & 49 \\ 8 & \text { G.T. } & 36 \\ 84 & \text { H. } & 7 \\ 38 & \text { I. } & 27 \\ 47 & \text { J. } & 26 \\ 25 & \text { K. } & 50 \\ 30 & \text { L. } & 14 \\ 14 & \text { K. } & 38 \\ 30 & \text { J. } & 19 \\ 78 & \text { H. } & 17 \\ 77 & \text { I. } & 8 \\ 25 & \text { M. } & 12\end{array}$

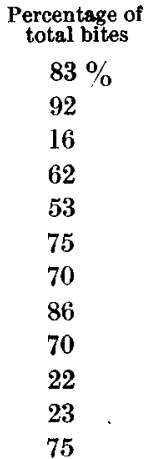

$\begin{gathered}\text { Total No. } \\ \text { of bites } \\ \text { recorded }\end{gathered}$
59
39
44
43
49
66
20
44
27
79
35
16

Out of the six persons who assisted in these trials two, owing to lack of opportunity, made the trial with one of the experimenters only, $L$. with A. B. and M. with $G$. T. and their records are consequently discarded when making a final comparison between the resistant powers of $A$. B. and $G$. T. For this purpose the percentages of the results may be arranged as under. The two trials between A. B. and G. T. are averaged and treated as a single trial.

\section{Table V.}

$\begin{array}{cccccccc} & \text { A.B. } & \text { G.T. } & \text { H. } & \text { I. } & \text { J. } & \text { K. } & \text { Totals } \\ \text { A.B. } & - & 12.5 & 84 & 38 & 47 & 25 & 206 \cdot 5 \\ \text { G.T. } & 87.5 & - & 78 & 77 & 30 & 14 & 286 \cdot 5 \\ \text { H. } & 16 & 22 & & & & \\ \text { I. } & 62 & 23 & & & \\ \text { J. } & 53 & 70 & 86 & \\ \text { K. } & 75 & 201 & \text { Totals of the percentage of bites received by the four experi- } \\ \text { menters H., I., J. } J \text { and K. in trials with A.B. and G.T. } \\ \text { respectively. }\end{array}$

From this it would appear that in the comparison of A. B. and G. T. alone the ratio of the mosquitoes' preference for G. T. is roughly 7 to 1 , but if the question is judged in relation to the other four experimenters in combination with $A$. B. and G. T. the ratio of preference is less than 3 to 2 ; while, if the comparison is made through the relation of the four persons H., I., J. and K. only, leaving the direct tests between A. B. and G. T. out of account, the preference is not far from parity. It is probable that this divergence in result, according to the inclusion or exclusion of some of the experimenters, is not a matter of pure chance, but the effect of the mosquitoes' preference being swayed by more than one factor; for instance, if the presence of a moist skin is one factor the temperature of the skin may constitute another, and the intensity or other characteristic of the odour arising from the skin yet another factor. 
As regards the moisture and temperature of the skin, some allowance is no doubt necessary for the individual periodic fluctuation of A. B. and G. T., but it does not seem probable that this could be of sufficient magnitude, especially under laboratory conditions, to greatly modify the results.

Our conclusion is therefore that some allowance must be made for the greater attraction of G. T. over A. B., and that for practical purposes it is safest to assume that this ratio is more likely to be 3 to 2 than either of the extremes.

\section{SUMMARY OF RESULTS.}

For the purpose of testing culicifuges numbers of Stegomyia fasciata (the Yellow Fever mosquito), bred in incubators, were placed in cages kept in the laboratory. The efficiency of the preparations was tested by coating the forearm with a definite quantity of one or other of them and exposing in a cage, each test being controlled by inserting after a short interval the other and untreated arm in the same cage, the number of bites being compared in each case. By this procedure it was hoped to obtain a measure of the relative protection which the culicifuges might be expected to afford when used under practical conditions against Anopheles mosquitoes.

In the first series of trials conducted within 15 minutes of application, eight preparations out of a total of $\dot{2} 2$ tested gave satisfactory results. Their active ingredients were (1) Oil of Cassia and Camphor, (2a) Oil of Cassia and Peppermint, (5) Oil of Eucalyptus and Citronella with Phenol, (9a) Crude Naphthalene (coke oven) and Camphor, (10) Crude "Parasitox," (15 a) Light Wood Oil, (21) Oil of Turpentine, (22 a) "Lawson's Anti-mosquito Compound." These preparations were then tested to ascertain for what period their protection could be depended upon. Preliminary trials indicated that this period was not likely to extend for more than two hours between treatment of the arm and exposure in the cage. None of the preparations gave complete protection in this series of trials; the most efficient were Nos. 1, 21, 2a, $15 a$ and $9 a$, over a two hours period.

It appeared, however, that the two experimenters were unequally attractive to the mosquito. Making allowance for this, preparations $2 a, 1,15 a$, and 21 were almost on a parity, followed by $9 a, 10$ and 5 in order. A series of experimental trials based on this element of preference on the part of the mosquito was confirmatory of the factor of preference and showed a ratio of attraction of about the order of G. T. 3, A. B. 2.

Observations on the behaviour of the mosquitoes during the tests suggest that the protection afforded does not result from a dislike of the insects to the culicifuge but to its obscuring the attractiveness of the human odour.

Regarding the make up of the essential ingredients it was found that fluid preparations were inconvenient and tended to be wasteful in application. Soap preparations, unless very soft, are apt to be difficult of economic use and in either case are more readily dissjpated by perspiration than waxy or greasy 
ones. Culicifuges prepared with grease are more easily applied but are not so lasting as those put up with wax. Soft wax preparations, correctly adjusted to the temperature in which it is proposed to use them, are most suitable for out of doors use, especially in the case of troops. The retarding of volatilisation caused by the admixture of the active ingredients with wax or grease is a distinct advantage, but care must be exercised in respect of the relative proportion of active substance to the base. The golden rule is to use as much of the active constituent and as small a quantity of the inert base as is consistent with convenient application and the prolonging of the period of efficiency, not, as most proprietary compounders appear to think, as little as possible.

In choosing a culicifuge for use, the human factor of choice in regard to pleasing and unpleasing odours should be as little disregarded as consistent with efficiency. Where large quantities are needed cost is an important consideration, but must not be allowed to endanger the willing co-operation of the individuals it is desired to protect.

\section{REFERENCE.}

Howard, Dyar and KNaB (1912). The Mosquitoes of North and Central America and the West Indies, vol. 1. pp. 260, 261. Carnegie Institute. Washington. 